\title{
THE ANTHROPOLOGY OF TACIT KNOWLEDGE IN THE DOMESTIC MANDALA: A CASE STUDY OF CHHETRIS IN THE KATHMANDU VALLEY
}

\section{John Gray *}

'F or our house is our corner of the world ... it is our first universe, a real cosmos in every sense of the word.'

Gaston Bachelard, The Poetics of Space

'W e know more than we can tell.'

Michael Polanyi, The Tacit Dimension

The epigraphs encapsulate the two major themes of this paper. As Bachelard's quotation suggests, Chhetri houses are not simply functional places for everyday living. Instead, the house and its surrounding compound are also an encompassing cosmos in which Chhetris of the $K$ athmandu Valley dwell and come to understand its fundamental principles. ${ }^{1}$ In their everyday activities of preparing, cooking and eating rice, Chhetri Householders spatially configure their domestic compounds into mandalas-sacred diagrams that are simultaneously maps of the cosmos and machines for revealing the truth of cosmos as a fundamental unity. At the same time, such everyday dwelling in a domestic mandalas is productive of knowledge of the cosmos they represent.

Polanyi's point 'we know more than we can tell' (1966:4) is a vital dimension for anthropology in explaining social and cultural life. Refocusing on what he calls 'the tacit dimension' redresses the tendency of

* Jhon Gray is an Australian Antropologist.

1 Se also Blier 1987, Kent 1990, Rapport 1969, Rudofsky 1964, Waterson 1991. 
anthropologists to rely on what people can and do say about their lifew orlds as evidence for the analyses and interpretations they construct. $Y$ et, much of the knowledge by which we live our everyday lives is tacit. In this paper, I highlight four aspects of the tacit dimension. First, it is not easily verbalised and activities can be meaningful even if the meaning is not able to be explained in words, explicit concepts or subject to reflection (Jackson 1966:34). 'This sort of [tacit] knowledge can be represented, made present-only through action, enactment, or performance (Fabian 1990:6, brackets added). Second, it is not just the case that tacit knowledge is not formulated linguistically and not available for reflection, rather its effectiveness in enabling everyday life is founded on it not being explicit and linguistic, (Bloch 1998:11), or use Polanyi's concept, it remains in our 'subsidiary awareness' (1958:55ff). Language is a good example. I am able to write in English for this paper without being reflexively conscious of or able to verbalise explicitly the knowledge of English grammar the rules about the use of nouns, verbs, pronouns, adjectives, adverbs, clauses, and stylistics-that linguists tell me I have in that enables me to do so. This is not to say that I don't have some rudimentary explicit and sayable knowledge about English grammar that I can bring into my focal awareness when I am analysing the grammar of what I am writing. But even though I do, such knowledge interferes with my explicit intention and ability to express my thoughts. If I try to bring my tacit knowledge of grammar into reflexive consciousness or focal awareness simultaneously with the intentional act of writing when my focal awareness is on what I am trying to express, it distracts me and inhibits me from my primary, pragmatic and explicit task of writing something about the anthropology of domestic architecture among the Chhetris.

In taking this stance, Polanyi joins a number of other anthropologists and philosophers who argue that our humananity emerges primarily through our everyday, practical engagement with the world rather than through a contemplative reflection upon the world (A rendt 1958, Heidegger 1962, Jackson 1996). Accordingly, there is a difference between the lived, often pre-reflective, immediacy of being-in-the-world and the distanced and reflexive accounts about being-in-the-world, between a pre-theoretical and praxical relation to the world-embodied actions of using and doing things in everyday life-and a contemplative 
and reflexive relation to the world. 'The knowledge whereby one lives is not necessarily identical with the knowledge whereby one explains life' (Jackson 1996:2). Such being-in-the-world and the practical knowledge for doing so, 'the knowledge whereby one lives', is to an important extent tacit and consequently embodied. This is the third aspect of the tacit. ' $M$ y body has its world, or understands its world, without having to make use of my "symbolic" or "objectifying" function' (M erleau-Ponty 1962:162). We are conscious with and through our bodies and we live in and constitute the world as embodied subjects. Fourth, this being-in and constituting the world as lived bodies is primordially spatial. Humans inhabit spaces through their body. We see, hear, feel and move in relation to things with our bodies and these things have a spatial relation to our bodies so that our inhabited space is constituted as bodily space. Through the lived body's consciousness and actions, we project ourselves into the world, embrace it, encompass it, and to use Heidegger's (1975:145) encompassing concept for this multifaceted praxis, to 'dwell' in it. We do not exist as conscious subjects without it; it doesn't exist for us without our consciousness. In this sense, body and the surrounding spatial environment are mutually constitutive; there is nobody outside its sensuous relations to the world.

Accordingly, a pervading ethnographic theme of this paper is the way Chhetri villagers come to understand their paradoxical world of prosperity and its renunciation through embodied spatial movement in their houses. As they move about their domestic compounds, they not only carry out everyday activities tasks such as entertaining guests, processing grain, preparing food, eating a meal that are in their focal awareness-but also tacitly build their houses into concentric mandalas, produce an embodied and revelatory knowledge of the enigma of being Householders and turn it into a' bodily hexis', that is, a permanent and corporeal disposition of thinking and feeling (Bourdieu 1977:93-94). Underlying their seeming ordinariness, Chhetri houses are also extraordinary; they are sacred spaces that re-iterate the Hindu cosmos-that's why I have called them D omestic M andalas. Ordinary everyday household chores and activities in Chhetris focal awareness are simultaneously extraordinary cosmogenic acts of building Chhetri houses into the cosmos and revelatory acts of tacit and embodied knowing its fundamental principles. 


\section{Chhetris}

The ethnographic focus of this paper are members of a clan of Chhetris living in a hamlet located in southern reaches of the Kathmandu Valley. The hamlet consists of approximately 100 household groups (pariwar), of which two-thirds are members of a single agnatic lineage. Household groups range in size from single person households (2), to nuclear households (39) and complex joint households (24). In most cases, each household group occupies a single 'house' (ghar) consisting of the house building and the compound that surrounds and encloses it. ${ }^{2}$

Chhetris explicitly understand their earthly existence in terms of the enigmatic nature of their lifeworld and the Hindu notion of the four states of life (ashrama). M any were able to articulate to me the idea that the human world consists of, on the one hand, a diversity of human individuals, social groups, material things and natural forces of the everyday life and, on the other hand, a transcendent and absolute unity that is a spaceless, timeless, causeless void. They understood the origin of this worldly diversity through the self-sacrifice of the primeval cosmic being, Purusha, who embodies the fundamental unity of the cosmos. ${ }^{3}$ As a result of Purusha's sacrifice, all perceptible time and space, every different corporeal being and thing, and all the variety of natural energies and forces in the everyday world are both distinct phenomena and an expression of the whole unified cosmos. To focus on the former as fundamentl is to experience reality as constituted only by the diversity of sensible worldly phenomena and to become attached to people and things through social and material relations (see Gray 1995). To pursue such attachments as the goal of life is to be shrouded in ignorance and to be caught in the continual cycle of death and rebirth. To focus on the latter as the fundamental reality is to experience the everyday world of diversity

2 There are some cases in which a joint family has split into two or more household groups and continue to occupy a single house structure until land and money is found to build two separate houses. In such cases, internal renovations are carried out so that each household group has at least a separate kitchen.

3 Rig Veda 'Hymn to Purusha' (I $0: X C)$. Purusha embodies the fundamental unity of the cosmos. All that can and will exist in the world is immanent in his body. $\mathrm{H}$ is self-sacrifice is a creative act unleashing the diversity inherent and potential in his body and establishing the microcosmic-macrocosmic system of correlations between planes of existence. 
as ultimately an illusion (maya) that hides the unity of the cosmos; such enlightened knowledge of the absolute leads humans to eschew the illusion of attachments and gain liberation or release (moksha) from the round of death and rebirth, that is, consigned to continual life-in-the-world of illusion.

It is in this context that Chhetris situate the four stages of life-inthe-world. The first stage is the Brahmacharya, the Life of the Celibate Student. This is the stage during adolescence when a young boy studies the religious texts under the guidance of a guru as a prelude to and a precondition for marriage and entering the Householder stage of life. During this phase, the boy adopts asceticism as a mode of life through celibacy and begging for food. Most Chhetri boys go through the Brahmacharya stage only as part of the rite of passage (Bartaman) in which they become adults. ${ }^{4}$ The second stage is the Grihastha, the Life of the Householder. This is the stage in which Chhetri men and women spend their adult lives; it is the stage for life-in-the-world, fully and actively engaging with the diversity of people and things motivated by practical, everyday concerns. It includes marriage, raising children, living in a household and producing the material needs for its members. The third stage is the $V$ anaprasta, the Forest D weller. This is the stage when, having discharged the duties of the Householder and passed the age of copulation, a man and his wife retire to the forest where they devote themselves to meditation and the practice of austerities including chastity. All of the previous stages are a preparation for the final and most radical renunciation demanded of the final stage of life, the Sanyasin, or Wandering A scetic. During this stage of life, a person renounces all worldly desires, together with the social relations and attachments entailed by them.

Chhetri villagers consider themselves to be in the H ouseholder stageof-life. They told me that every Chhetri boy had gone through Bartaman and they could not remember anyone from their hamlet who had become a Forest Dweller or a W andering Ascetic. In effect, the four stages-oflife are reduced to a juxtaposition of two possible modes of being-in-theworld. One is the Householder, the ordinary person-in-the-world whose

4 For women, the rite of passage to adulthood and to the Householder stage of life is marriage. 
life is defined by Grihasta dharma that motivates actions (kaman) and the aim of such action is to produce 'practical' and beneficial results ('fruits') in this world. It is this action in and for the world that both produces and engages the diversity of people and material things which are the objects of one's attachments, desires and passions. But as a result of such worldly-oriented action and attachments, the Householder is caught in the continual round of birth-death-rebirth into the world. The other mode of being-in-the-world is the Renouncer, personified by the asceticism and detachment of the Brahmacharya, Vanaprasta and Sanyasin. The goal of such detachment is to achieve liberation from the round of birth-death-rebirth and to realize the fundamental unity of one's self with all other selves and things.

Chhetris' lifeworld is both practical and cosmological: as they engage in everyday domestic activities, they are fulfilling their sacred duties. As Householders, their aim is to prosper not just in the narrow sense of material wealth but also in the wider sense, captured by the Nepali word Samyddhi, of an abundance of those things that characterize the 'good life': children, health, well-being and peaceful relations with oneself, other human beings and the deities. At the same time, they are also enjoined to remain detached from these manifold worldly attachments, to resist enslavement by them (Madan 1987:3) in order to achieve liberation by seeing through the veil of illusion that conceals the fundamental unity of the cosmos. Their goal is to live a life characterised by detached attachment or passionless passion.

\section{Chhetri Houses}

The house is the primary locus and focus of the Householder's life-inthe-world. In the hamlet where I worked, there are two types of houses

5 G rihasta dharma includes three main duties: begetting children, feeding the ascetics, and performing sacrifice. Each of these motivates $\mathrm{H}$ ouseholders to a life characterized by passion, prosperity and attachment (see Gray 1995): the duty to beget children motivates an attachment to a diversity of people (epitomized by marriage and the love of children); the duty to feed the ascetics motivates attachment to a diversity of things in the world (epitomized by ownership of land to produce food for subsistence and to feed the ascetics); and the duty to perform sacrifice motivates attachment to a diversity of deities (epitomized by doing numerous pujds towards gods and goddesses). 
usually consisting of two storeys. ${ }^{6}$ One type I will call 'traditional' (see Figures $(\mathrm{a}$ and $\mathrm{Ib}$ ) built with sun-, dried mud bricks, carved wooden window frames and doors, mud floors, and tile or thatched roofs. They generally have an open plan ground floor with four visible pillars forming a rectangle around a central pillar, a kitchen in far corner often behind a low all to obstruct visibility from doorway, and a worship room generally located on the second floor. The other type of house I call 'contemporary' (see Figures $2 \mathrm{a}$ and $2 \mathrm{~b}$ ), indicating its more recent construction using concrete for wall construction with wooden windows frames and doors. The main difference is that these newer houses have separate rooms rather than open plan with kitchen located in the room furthest from the main entrance or on an upper floor.

Although they are distinguished by the building materials and interior room layout, there are four common architectural features. First, houses are built on rectangular sites surrounded by a low wall that defines the boundary of the domestic compound. They are located towards one edge of the site away from approaching public roads or paths, leaving space for a courtyard. This results in a configuration of nested domestic spaces boundary, courtyard, verandah, main entrance and interior of house (see Figures 1 and 2). Second, the houses are oriented with the main entrance opening out onto the courtyard allowing household members a clear view of it and anyone who may be approaching the house from the public path or roadway. Courtyards are distinct spaces and one of their important architectural functions is mediating between the house and public thoroughfares outside the boundary of house compound that are potentially dangerous places where impure people of lower castes (jat), malign witches (boksi) and malevolent ghosts and other spirits (bhut, pret, pichds) linger. Third, a covered and raised verandah spans the front of the traditional houses and some portion of the front of contemporary houses; its location makes it another mediating space, now between the courtyard that is visible and the interior of the house that is not visible to those outside the compound. Finally and most

6 When I began fieldwork in 1973, all the houses were of the traditional type. By 2001 , traditional houses were in the minority (31 of 69), as over the intervening years a significant number of Chhetris had built contemporary ones. M ost of these new houses were built by young men after their marriages as part of the process of separating from their joint families and establishing separate household groups. 
importantly, both types of houses are in the spatial configuration of a mandala.

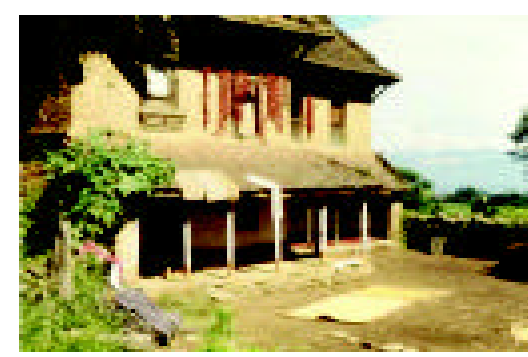

Figure 1a: Traditional House

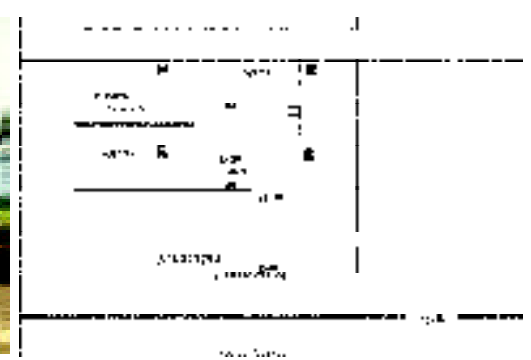

Figure 1b: Sketch Plan of Traditional House (ground floor)

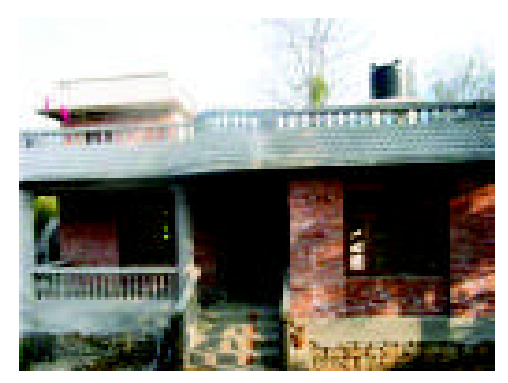

Figure 2a: Contemporary House

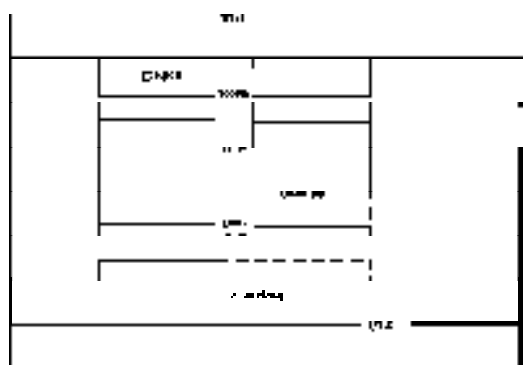

Figure 2b: Sketch Plan of Contemporary House (ground floor)

\section{The Mandala Form}

A mandala is a mystic diagram that represents the nature and order of the universe (see Figure 3)-'map of the cosmos.. . the whole universe in its essential plan' (Tucci 200L 23). ${ }^{7}$ Tucci's description highlights three important attributes of the mandalas. First, their primary referent is the

7 In N epal 'mandala' tends to refer to mystic diagrams associated with the Buddhism of N ewars and Tibetan groups and 'yantra' with the $\mathrm{H}$ induism of Brahmin-Chhetris. See Figure 3. At the same time, it should not be concluded that 'mandalas are rarely part of the Hindu tradition and than yantras are not found in the Buddhist tradition' (Buhnemann 2003:16). See Gellner's description of the importance of mandalas among both Buddhist and Hindu N ewars of Patan (1992:45-8,190-1). Buhnemann (2003) and Brunner (2003) provide discussions of the differences between mandalas and yantras based upon analysis of $\mathrm{H}$ indu textual sources. BU hnemann concludes: 'The use and functions of these terms [mandala, yantra and cakra] are complex and it will be impossible to arrive at a universally valid definition' (2003:18). 


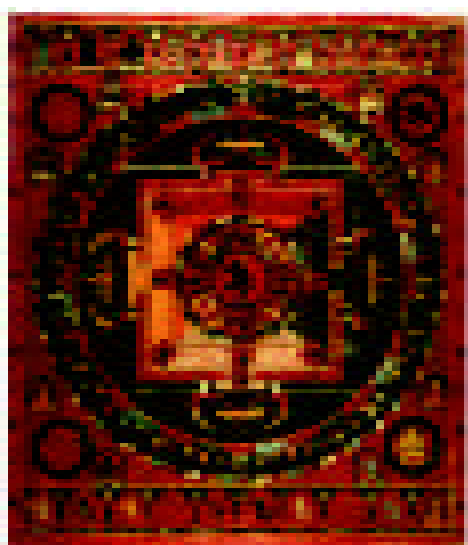

Nairatma Mandala ${ }^{8}$

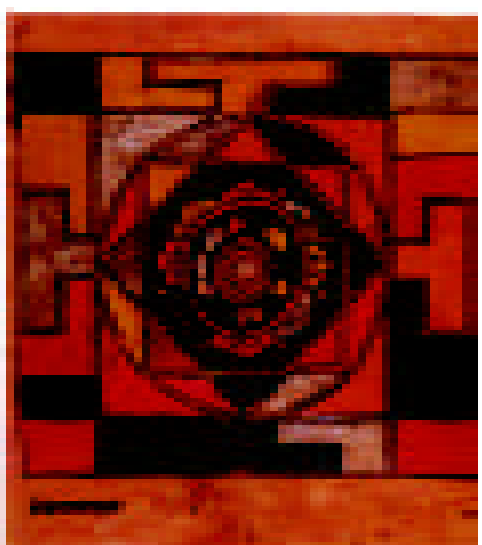

Nepal, c. $18^{\text {th }}$ century ${ }^{9}$

Figure 3 Two forms of the mandala

cosmos that may be represented in different graphic modes: pictographs composed of pictures and icons that depict religious concepts and deities who in turn personify the primary bodies and natural forces of the universe as well as the qualities of humans; geographs composed of purely geometric designs-squares, circles, triangles and the point whose shapes likewise stand for religious concepts, deities and the natural forces and human qualities they personify. Second, they are maps of the cosmos and, as such, the spatial arrangement of the pictures and geometric el ements in the composition depict important characteristics of the cosmos. Third, more than just an allegorical map of the cosmos, mandalas are microcosms of it. Whether composed of pictographic or geometric elements, they are revelatory of the fundamental unity of the cosmos as well as the normally hidden system of correlations between planes of existence immanent in that unity: the cosmos, the deities, the human world, and the body and psyche of the individual (Hopkins 1971:25, Tucci 2001:45); 'knowledge of such mystical connections leads to power...' (Gourdriaan 1979:57-58) and is a basis for ritual action and its efficacy (see Daryn 2002: 164ff).

8 From 'Early Tibetan Mandalas: The Rossi Collection'. With the kind permission of Rossi \& Rossi Ltd., London.

9 Ajit M ookerjee Collection. From Yantra: The Tantric Symbol of Cosmic U nity, by M adhu Khanna, Thames and H udson, London. 
A gain, despite their differences in representational form, mandalas share fundamental compositional design elements for expressing this cosmology and providing a 'machine' (Zimmer 1972:141) for revelatory knowledge: as a whole they are oriented to the cardinal directions each of which is associated with a deity; they have a centre point (bindhu) surrounded by a concentric girdle either circular or polygonic of line/s and space/s that provide the dynamic quality of movement; and they have outer boundary line enclosing a sacred space. This spatial configuration is constructed from three primary geometric elements: the square, the point and the circle, each with representing a fundamental dimension of the cosmos.

The square is the perfect four-cornered polygon with sides of equivalent length intersecting at right angles. In Hindu iconography, it is the geometric image of the space for terrestrial dwelling; it creates the spatial abode in-the-world for deities and humans. Its orienting references are the cardinal directions. The four sides and the cardinal directionseast, south, west and north are mutually constitutive. In the process of creation, the cardinal directions and terrestrial space are the source of each other's existence. The four corners formed by the intersecting sides produce the intermediate directions south-east, south-west, north-west and north-east. The eight directions are, in turn, associated with deities representing and reigning over particular aspects of the cosmos they personify the cosmos manifest in the planets, natural forces, and human qualities. ${ }^{10}$ By focusing on these elements, we can abstract from the complex mandala a basic design configuration consisting of a four-sided, four-corned polygon aligned with the cardinal directions surrounding a centre. In this configuration, the emphasis is on the terrestrial world as a space of human habitation created and defined by the sacred geography of the cardinal directions and their reigning deities. In this configuration (see Figure 4), the mandala is a cosmological space for auspicious action in-the-world. The directions and their reigning deities have distinct qualities and meanings that organize terrestrial space into a template for orientating human action. Chhetris try to align their action in particular

10 These essential features of the square-a four-sided polygon implicating and oriented by the four cardinal and four intermediate directions-are retained in the rectangle which we will see is the basic geometric configuration of a house. 
directions-either by physically performing it in a particular part of a structure or diagram or bodily facing a particular direction during actionso that the nature of the action is compatible with the quality or characteristic of the direction toward which it is aligned. Such harmonious and auspicious alignment portends beneficent outcomes for the actions through which Chhetri Householders engage with and form attachments to the diversity of people, things and deities of the world in order to achieved a prosperous life in-the-world.

The point (bindhu) and its central location in the diagram together are a spatial rendering of the fundamental unity and truth of the cosmos in its un-manifested form before and after space, time and the diversity of beings and things of the world. Like Purusha, all is immanent in it; it is the point from which the world in all its diversity is created and it is the point into which all creation dissolves. M ovement outward from the bindhu that forms a surrounding space is the force of creation and evolution of worldly diversity and the entrapment of attachment to it; movement inward toward the bindhu is the force of dissolution and devolution of worldly diversity and liberation from its illusory power through knowledge of the fundamental unity.

The circle defines another type of space, a concentric zone around the all-embracing centre point without reference to the cardinal directions. The concentric zones do not immediately suggest the expanse of terrestrial space of human living but the space created by and for the diversity of people and things. Its orienting reference, then, is the centre point 'as the universe in its un-manifested form' (M ookerjee and K hanna 1977:96), 'as the principle from which all form and creation radiates' (Buhnemann 2003:41). The zone/s marked out by concentric spaces around the bindhu depict the dynamism of the cosmos-simultaneously the outward, expanding, centrifugal act of creating from the centre point the diversity of things and beings, as well as the space for them, and the inward, contracting, centripetal act of their dissolution into the centre point. By focusing on the point and surrounding concentric zones elements, we can abstract another basic design configuration consisting of concentric zones around a point (see Figure 4). In this revelatory configuration, the mandala is a guide for understanding the cosmos, whether achieved by meditation or action upon its form. In sensual and embodied 
Revelatory Configuration: concentric zones around a powerful centre

\section{Auspicious Configuration: oriented by cardinal directions}

Figure 4: Two Configurations of domestic sp

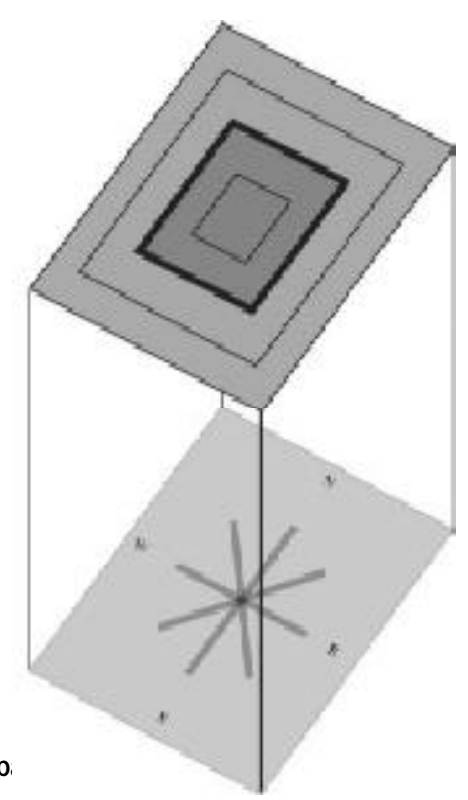

contemplation, as the eye fixes on the centre point and is drawn to move outward by the surrounding lines, the beholder experiences the unmanifested source, visualizes the creation of the diversity of people and things and feels the attachment to the world that traps humans in the round of death and rebirth. As the eye is pulled inward by the power of the bindhu at the centre, the beholder experiences the obliteration of diversity, discovers the illusion of attachment to it and comes to understand the true nature of the universe as fundamentally a timeless and spaceless unity in which all forms of individual consciousness merge in the centre.

\section{Chhetri Houses as Auspicious}

As can be seen from the photos and sketch diagrams, Chhetri houses have the three characteristics of the auspicious configuration of the mandala: a four-sided polygon oriented to the cardinal directions with a materially or ritually established central pillar. Chhetris intentionally build this configuration into their houses through three interweaving 
processes of construction. ${ }^{11}$ The first is the material construction of the house which has a number of stages: selecting the site, preparing the site, positioning the house on the site, laying the foundation and building the external structure, and finally inhabiting the house. The second is linking these stages of material construction to the flow of cosmic time so that they take place at auspicious times calculated by the household priest to be compatible with the horoscope of the owner. The third process is making the house an auspicious place for domestic activities, portending well-being and prosperity for the owner and his household group. This involves creating an harmonious spatial conjunction between the house and the space in which it is built, a space that is created in the act of building. Spatial auspiciousness entails ensuring compatibility and harmony between the physical structure and the spatial milieu in which the house is erected: during the process of selection of the site, worship is performed to the Deity of the Earth (Bhumi Puja); before the laying of the rectangular foundation, a' Foundation Ritual' (J ug Puja) is performed. In this rite, idols of deities associated with the cardinal directions are buried in the four corners and another in the centre of the rectangle. When the foundation is laid, these deities become part of the house structure itself and orient it auspiciously to the cardinal directions. In addition, rites are performed to neutralise evil or harmful presences from the land and the house itself.

This theme of auspiciousness is carried through into the spatial layout as well. U sing what they call 'bastu rules' 12 , Chhetris situate particular types of spaces auspiciously in relation to the cardinal directions. The three most important are the main entrance, the worship room and the kitchen. The main entrance is in most cases oriented to the south for two reasons, at once practical and cosmological. First, it situates the courtyard so that it receives the warming sun during the cold winter months. Second, while the south is the inauspicious direction of the Yama, the deity associated with death, when entering the house, people are facing north, the auspicious direction of the deities so that movement into the house

11 See Levy for a description of the Newar house as al so an interweaving of the material and the symbolic (1990:186-192)

12 This is the only reference they made to the Vastu Shastras in explaining the orientation and layout of their houses. 
towards the north portends the beneficence of the deities. The worship room should be in the north-east, the direction of the deity Isan, god of purity, knowledge and wisdom the state, outcome and benefit of performing puja. In the majority of houses $(66 \%)$ for which I have detailed room layout plans, the worship room is located in the north-east; in those houses in which the worship room is located in another quadrant of the house, the worship alter and idols are located in the north-east corner of the room itself. The kitchen with its cooking fire should be in the south-east, the direction of the deity -A gni, the god of fire. However, in most Chhetri houses $(72 \%)$, the kitchen is in the northern quadrant. This pattern makes sense in relation to the location of the main entrance in the southern quadrant: placing the kitchen in the northern quadrant of the ground floor means that it is the space or room farthest from the main entrance. When looked at according to the location relative to the main entrance, rather than aligned with a cardinal direction, almost all kitchens in traditional and contemporary houses are located far away from the main door either by being placed in the farthest corner or room of the ground floor or on an upper floor. The presented me with a different way of understanding the location of the kitchen-as the centre of the revelatory configuration of the domestic mandala.

\section{Chhetri House as Revelatory}

Bourdieu developed the concept of 'bodily hexis' (1977:93) to describe the way in which the knowledge and dispositions through which we conduct our everyday lives have not just a reflexive form in ideas and concepts that we may be able to verbalize but also a tacit form (see Polanyi 1958, 1966) in the gestures and movements of the body. This duality of the verbal/reflexive and tacit/corporeal characterizes the forms in which Chhetris experience cosmological ideas, build them into their houses, and their houses into mandalas. To paraphrase Bourdieu: 'Bodily hexis is [cosmology] realized, em-bodied, turned into a permanent disposition, a durable manner of standing, speaking, and thereby of feeling and thinking' (1977:93-4, bracket added). Bodily hexis entails moving in space and such motility creates culturally significant spaces. In the remainder of the paper, I describe how Chhetris create concentric spaces of inclusion and exclusion through the durable patterns of 
household activities and movement in their compounds (see M unn 2003). This creation is mediated by their everyday concerns with maintaining purity and avoiding the dangers of impurity. These concerns about purity and impurity transfigure the abstract cosmological concepts of diversity and unity, attachment and detachment, illusion and revelation into everyday bodily practices of purity and impurity and one of the most important of these are activities of cooking and eating in the kitchen.

\section{Purity and Impurity}

For Chhetris, being Householders means that there are no more important media for living in the world than their bodies and the food they eat to sustain them. Like Hindus throughout South A sia, they identify substances produced by the body-saliva, perspiration, urine, excrement, blood, semen and mucus as the primary sources of impurity (jutho) as well as the product and signs of embodied life-in-the-Householder'sworld. Eating is paradigmatic of actions that cause impurity. When people eat, the food they touch as well as the hand which conveys the food to their mouths become polluted with their own saliva. These sources of impurity are all substances that flow from the inside to the outside of the body and the impurity they produce is the result of transgressing its boundary. This means that the vital, life-maintaining organic processes inherently 'produce' impurity. Chhetris cannot avoid them as part of their physical being-in-the-world just as they cannot avoid the passions and attachments of their moral being-in-the-world as Householders. This parallel necessity of, on the one hand, corporeal life and the impurity it entails and, on the other hand, the dharma of the Householder and the attachments it entails suggests that impurity is the everyday bodily transfiguration of attachment and by implication that purity is the everyday bodily transfiguration of detachment.

\section{Purity as Detachment}

Purity is a state of perfection characterized by a completeness, wholeness and integrity that has not been corrupted by human action (see Madan 1987:58ff) or by breaching the boundary between inside and outside. Maintaining or restoring purity entails bodily deeds of detachment and asceticism. Bodily-produced impurity is personal and temporary. It is personal in the sense that only the individual whose 
body produces the impure substance necessarily becomes impure. It is temporary in the sense that a state of purity is easily restored by two kinds of activities-cleansing and abstinence. In cleansing, impurity is removed and the integrity of the body's boundary restored with running water that courses over the body and flows away. This is effective because water has the property of absorbing the quality of the object with which in comes into contact. For this reason, cleansing always involves water flowing over the impure part of the body, taking the impurity it has absorbed away from the body, thereby re-establishing its wholeness by creating a separation from the organic substances which breached its boundary. The physical separation from polluting organic substances effected by bathing is a sensual practice of detachment from the corporeal life of the Householder and the worldly attachments it necessarily entails and from which it is impossible-like organic life itself-to abstain. By cleansing after coming into contact with impurity inevitably produced by the processes of the body, Chhetris perform and experience their detachment from these processes.

The other method of purification is ascetic practice, usually consisting of abstinence from eating and copulation, activities which produce impurity. Such abstinences involve avoidance or non-involvement with things of worldly enjoyment-good-tasting food and the physical pleasure of sexual intercourse. They are metonymic of a Householder's lifeworld and the necessary attachment to and/or passion for people and thingsfood, kinship relations and sexual relations. The purity achieved by abstinence from such passions and pleasures is another corporeal experience of detachment in the midst of the attachments of everyday life.

\section{Impurity as Attachment}

Impurity also has a permanent and collective form associated with castes whose members are affiliated through current or presumed historical practice with occupations that require contact with the impure substances or actions of others' bodies: Washermen with other people's sweat in the clothes they wash, Tailors with the skin of dead animals used in the drum they play at weddings, and Leatherworkers with the skin of dead animals in making shoes. In these castes, the occupation involves not just physical contact with pollution but also a permanent and excessive 
attachment to it in the sense that the activity is understood to have traditionally provided the means of subsistence. People engaging in these occupations embody such impurity and pass it on genealogically so that collectively the pollution defining them as a distinct caste group is part of their corporeal substance. Even if a particular person in one of these castes does not engage in the traditional occupation, $\mathrm{C}$ hhetris still insisted that he or she still embodies the collective impurity of the caste through genealogical transmission.

If the body is the source and locus of impurity as the everyday transfiguration of attachment, food and water are its main conductors. Caste groups in Banaspati are characterized and ranked as 'caste groups from whom drinking water is accepted for consumption' (pani chalne jat) and 'caste groups from whom drinking water is not accepted for consumption' (pani nachalne jat). Within the former category there is a further hierarchised division between 'castes from whom boiled rice is accepted for consumption' (bhat chalne jat) and 'castes from whom boiled rice is not accepted for consumption' (bhat nachalne jat).

Such an extended and elaborate ensemble of concepts and practices about the dangers of impurity transmitted through food and physical contact renders the preparations and consumption of food not just explicitly nutritionally essential and socially sensitive but also tacitly significant cosmologically. It is through the patterns of intentionally including and excluding impure people from the increasingly interior concentric zones of the domestic compound-courtyard, verandah, and kitchen-where rice is prepared and eaten that Chhetris have in the focal awareness the protection of themselves and their food from the impurity of low caste people, and, at the same time, they tacitly map the cosmos onto their domestic compounds, building them into a mandala of concentric zones around the kitchen as the centre (see Figure 5).

\section{Courtyard}

The courtyard is the space most visible from outside the low boundary wall and most vulnerable to the impurity and dangers of impure people from outside the compound. It is the place where raw grains are dried or processed. When rice is harvested in autumn, it is threshed in the fields 
and brought to the house as paddy (dhan) to be dried in the sun before milling. Once milled to remove the chaff, rice (chamal) is in the next stage of its transformation into food. A fter milling, the courtyard is the place where rice is winnowed to remove the remaining chaff. It is still considered raw because it is uncooked and it has not been subjected to human action corrupting the wholeness of the grains. It is in the process of cooking that the grains become vulnerable to the impurity of lower castes.

Because raw grain is immune from impurity, there are few, if any, protective spatial exclusions. The courtyard is the place where anyone is allowed to enter relatively freely. In this respect, the courtyard is the only place where members of untouchable castes can enter, as the case of the Tailor making clothes illustrates. The reverse is also the case: Chhetris do not fear becoming impure by entering the courtyard of low caste people.

\section{Verandah}

The verandah mediates the visible courtyard and the invisible interior of the house. Since it runs across the front of the house which faces into the courtyard, it is, like the courtyard, visible from outside the boundary. But like the house interior, the verandah is also a raised area above the courtyard on the same level as the house's ground floor and it is covered by a roof. Its architecturally mediating character is matched by its use as a socially mediating space between the public courtyard and the more secluded house interior. In traditional houses, there is often a raised wooden platform at one end of the verandah that people use for sitting in the sun and entertaining guests accompanied by snacks; in contemporary houses, either chairs or a grass mat are brought out for host and guest. In terms of spatial inclusions and exclusions, the visitors and guests entertained by $C$ hhetris on their verandahs are most often people of equivalent purity. They sometimes sit and talk with people of lower castes from whom they will accept water but snacks are not offered. People of untouchable castes (from whom they will not accept water) are usually not allowed on the verandah, particularly when snacks are being served. 
These spatial inclusions and exclusions are imposed because the method of preparing the snacks makes them more susceptible than raw paddy and uncooked rice to impurity and danger. Snacks are prepared inside the house where, in the process of converting raw grain into an edible state, the food, the preparer and the cooking process are out of sight and touch of people in courtyard and on the verandah. The most common snack is tea served with a small metal bowl of rice flakes, raw milled rice that has been boiled, then roasted and finally pounded into rice flakes. Alternately, dry-popped maize, dry-roasted soybean or commercially made biscuits may be served with tea.

Because of their method of preparation, rice flakes and other snacks are susceptible to impurity, but less so than other forms of cooked food. When rice or other grains are cooked, they are placed in a mediumeither water, oil or air (dry)-and heated over a fire rendering them porous, that is, the boundary of the grain becomes permeable and open to absorbing the qualities of the medium in which it is being cooked. The medium absorbs and conducts to the food the impurities of anyone who touches or sees the grain with evil intent during its transformation from raw to cooked. Different cooking media have different potentials for absorbing and conducting: water is the most, air the least and oil in

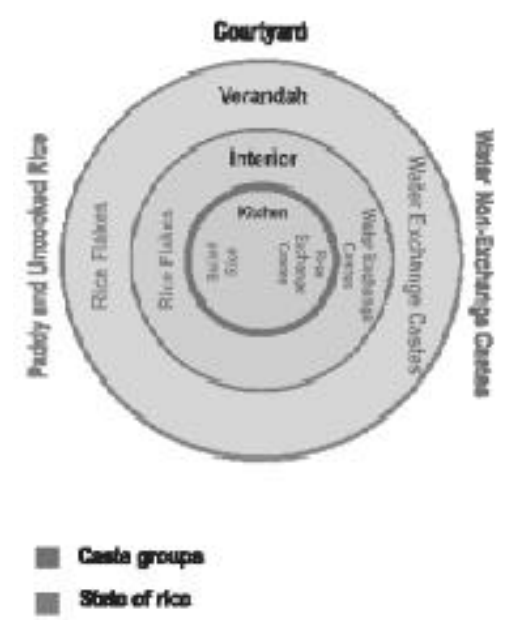

Figure 5: Concentric Configuration of Domestic Mandala 
between. The snacks served on the verandah are doubly shielded. First, they are cooked inside the house out of touch of low caste people who might be in the courtyard. Second, they are cooked and served dry (sukha) to guests without further cooking or preparation.

Compared to the courtyard, the verandah is more 'interior'. By this, I am referring to the increasing need to protect the purity of food with spatial exclusions upon people from outside the household group because the snack served is cooked and more vulnerable to impurity and danger than the raw grains dried and winnowed in the courtyard.

\section{Kitchen}

Chhetris eat two main meals each day, usually consisting of lentil broth, a curry of vegetables and/or meat and rice cooked in water (bhat). Water is the most transitive medium because it readily absorbs the character of any object with which it comes into contact. As a result, it can purify as well as pollute. In purificatory bathing, water flows over the object or person, absorbs the pollution and takes it away into the ground. Conversely, while it is boiling, rice sits in water which conducts the state of the cook to the permeable rice.

Because of food's openness to absorption, cooking and eating in the kitchen are dominated as much by an explicit concern with protecting the purity of the food, the people who eat it and the place where it is cooked and eaten as by the practical tasks of preparing food and consuming it (see Daryn 2002: 30-1). The kitchen in traditional houses consists of an earthen stove in the corner of a raised earthen platform (see Figure 6). Women told me that mud is a very absorptive surface that is particularly prone to pollution from eating bits of food made impure by saliva may fall on the ground so they must sweep and seal the floor with a purifying mixture of cow-dung and water after every meal. In some contemporary houses, where the kitchen is a separate room with floors of less or non-absorptive concrete, marble or other hard surfaces, the floor need only be washed with water after each meal to remove impurity.

The kitchen has the most exclusive spatial prohibitions. Only Brahmins and other Chhetris, the castes from whom they will accept cooked rice, were allowed to enter Chhetri kitchens when meals were 
being prepared and eaten. People of the water-acceptable castes were allowed to enter the verandah during a meal; they were occasionally allowed to come just inside the main entrance to ask a question but they could not enter the kitchen. When food was not being prepared or eaten people of water-acceptable castes could enter the kitchen, but I never saw this happen. Untouchables (water-unacceptable castes) could not even enter the house of a Chhetri without causing defilement of all the living spaces, public and private. Thus whenever an Untouchable wanted to interact with a Chhetri, he or she had to remain in the courtyard and call out to the householder.

Compared with the courtyard and verandah, the kitchen is the most interior of domestic spaces. For Chhetris, it is the room where their food and their bodies are most vulnerable impurity and danger so they do their utmost to ensure it is pure by locating it in the most inaccessible place, purifying it before and after eating and imposing the most exclusive spatial prohibitions on people entering it. Taken together, courtyard, verandah and kitchen form a concentric series of increasingly exclusive interior spaces where rice and the people eating it are increasingly vulnerable to impurity and danger, and where maintaining and protecting purity is increasingly important.

\section{Everyday Practice, Cognitive Knowledge and Embodied Revelation}

What I have tried to illustrate is that among Chhetris, their knowledge about equivalences between various planes of existence means that the activities of everyday domestic life and the places where they take place are multifaceted-corporeal, social and cosmological. In their focal awareness, eating nourishes the organic body, pollutes the social person, and is also an embodied experience of a Chhetri Householder's tacit understanding of the consequences of attachment, illusion and the entrapments of life-in-the-world. Similarly, their washing after eating to explicitly clean the body, cleanses the social persona of impurity and is the embodied experience and tacit understanding of detachment and renunciation so central to balancing the attachments of the Householder's life-in-the-world. Concomitantly, in carrying out these activities, Chhetris create multifaceted concentric spaces in their house-at once explicitly functional and social and tacitly cosmological-that form a mandala. Their 
houses likewise are multifaceted: they are places to live their daily lives, they are maps of the cosmos, and they are machines for revelatory knowledge.

I end by paraphrasing a passage from Clifford Geertz's who also sought to reveal the extra-ordinary in ordinary Balinese Cockfights (1975:450-451):

Enacted and re-enacted, so far without end, the house as mandala enables the people to see a dimension of their own subjectivity. As they live in their houses day after day, with the active living of a Householder producing prosperity and maintaining purity, they grow familiar with it.

$Y$ et, because ... that subjectivity does not properly exist until it is thus organized, the house as mandala generates and regenerates the very subjectivity it pretends only to display. Quartets, still lives and houses are not merely reflections of a pre-existing sensibility allegorically represented; they are positive agents in the creation and maintenance of such a sensibility.

\section{R eferences}

A rendt, H. 1958. The human condition: a study of the central dilemmas facing modem man. Chicago: University of Chicago Press.

Blier, S. P. 1987. The anatomy of architecture: ontology and metaphor in Batammaliba architectural epxression. Chicago: University of Chicago Press.

Bloch, M. 1998. How we think they think: anthropological approaches to cognition, memory and literacy. Boulder, Colorado: Westview Press.

Bourdieu, P. 1977. Outline of a theory of practice. Cambridge: Cambridge University.

Buhnemann, G. 2003. MaSdala, yantra and cakra: some observations. In G. Buhnemann (ed) $M$ aSdalas and yantras in the Hindu traditions. Leiden: Brill.

Daryn, Gil. 2002. Himalayan encompassment: man, cosmos and rice in a brahmin community in central Nepal. Ph.D. Thesis, Cambridge University.

Fabian, J. 1990. Power and performance: ethnographic explorations through 
proverbial wisdom and theatre in Shaba, Zaire. Madison: University of Wisconsin Press.

Gourdriaan, T. 1979. Introduction, history and philosophy. In S. Gupta, D. J. Hoens, and T. Gourdriaan, Hindu Trantrism. Leiden: E.J. Brill.

Geertz, C. 1975. Deep play: notes on the Balinese cockfight. In C. Geertz, The interpretation of cultures. London: Hutchinson.

Gray, J. N. 1995. The Householder's world: purity, power and dominance in a Nepali village. Delhi: Oxford University Press.

Heidegger, M. 1962. Being and Time. New Y ork: Harper and Row.

Heidegger, M. 1975. Building, dwelling, thinking. In Poetry, language, thought. N ew Y ork: Harper and Row, Publishers.

Hopkins, T. J. 1971. The Hindu religious tradition. Belmont, California: Wadsworth Publishing Company.

Jackson, M. 1996. Introduction: phenomenology, radial empiricism, and anthropological critique. In M. Jackson (ed) Things as they are: new directions in phenomenological anthropology. Bloomington: Indiana University Press.

Kent, S. 1990. Activity areas and architecture: an interdisciplinary view of the relationship between use of space and domestic built envrionments. In S Kent (ed) Domestic architecture and the use of space: an interdisciplinary cross-cultural study. Cambridge: Cambridge Univesity Press.

Levy, R. L 1990. Mesocosm: Hinduism and the organisation of a traditional Newar city in Nepal. Berkeley: University of California Press.

M adan T.N. 1987. N on-renunciation: themes and interpretations of Hindu culture. Delhi: Oxford University Press.

M erleau-Ponty. M. 1962. Phenomenology of perception. London: Routledge.

Mookerjee, A. and M. Khanna. 1977. The tantric way: art, science, ritual. London: Thames and Hudson.

M unn, N. 2003. Excluded spaces: the figure in the Australian A boriginal landscape. In S. Low and D. Lawrence-Zuniga (eds) The anthropology of space and place: locating culture. Oxford: Blackwell Publishing.

Polanyi, M. 1958. Personal knowledge: towards a post-critical philosophy. Chicago: University of Chicago Press. 
Polanyi, M. 1966. The tacit dimension. Gloucester, M ass.: Peter Smith.

Rapoport, A. 1969. House form and culture. Englewood Cliffs: Prentice-Hall. Rudofsky, B. 1964. Architecture without architects. London: A cademy Editions.

Tucci, G. 2001 [1961]. The theory practice of the mandala: with special reference to the modem psychology of the unconscious. Mineola, NY: Dover Publications.

W aterson, R. 1991. The living house: an anthropology of architecture in SouthEast Asia. Singapore: Oxford U niversity Press.

Zimmer, H. 1972. M yths and symbols in Indian art and civilization. Princeton, NJ: Princeton University Press, Bollingen Series VI. 